\title{
Population Ageing and the State of the Elderly, with Emphasis on Aged Jamaicans
}

\author{
Paul Andrew Bourne* \\ Northern Caribbean University, Mandeville, Jamaica \\ *Corresponding author: Paul Andrew Bourne, Adjunct Faculty, Northern Caribbean University, Mandeville, Jamaica
}

Submission: 侮 February02, 2018; Published: 佔July 05, 2018

\begin{abstract}
Objectives: The measurable goals of this paper are twofold. One, it seeks to review population ageing in the Caribbean and by extension in Jamaica, and to show some of the likely issues surrounding this phenomenon. Two, accompanying the 'graying of the Jamaica's population are problems associated with their health, and the fact that their quality of life should be in keeping with the mind, body and socio-cultural conditions.

Result:The ageing of Jamaica's population is as a result of the its decline in fertility which began in the 1960s coupled with the reduced mortality that owes itself to improvements sanitation, public health and the discovery of the pen insulin. It is primarily not the scientific invention of pen insulin that accounts for the lowering of mortality in Jamaica and around the world, but it is widespread use and acceptance of the product by the publics. With these conditions, the 'greying' of the Jamaica's populace means that significantly more burden will be levied on the working age population because there will be more elderly to take care of. Such a situation will be problematic in the future, as this is associated with increased pension payouts, higher health-care expenditure, along with the accompanying demand changes that are inevitable in meeting the needs of the ageing population.
\end{abstract}

Method: The approach is the use of statistical reports, artifacts and records along with employing of the historical comparative method of data analysis.

Conclusion:Ageing is not a recent phenomenon. It goes back centuries, from time immemorial. Importantly, the aged are on the upper end of the ageing spectrum; and this affects the population dynamics of the society. Ageing inevitable means longer life, that affects the population composition and structure. Therefore, as the population ages, the base of the population pyramid narrows, while the upper portion expands, and this is dependent on fertility reduction and mortality declines. If reduced fertility continues without any major catastrophe in the future, what we are likely to experience is people living longer, and the death rates at older ages will begin to increase thereby changing the population age structure further. Among the challenges of population ageing is not the least being changes in the population pyramid but what it is the health conditions that arise from biological ageing.

Keywords: Ageing in jamaica; Ageing in selected caribbean states; Biological ageing; Chronological ageing; Demographic ageing; Demographic transitions; Elderly; Population ageing; State of elderly people; Wellbeing

\section{Introduction}

Ageing is not a recent phenomenon; it goes back centuries. Currently, the differences are pace and level. The distinction here is, pace denotes the rate of growth per annum; and level represents the percentage of the population who are experiencing a certain event. These concepts will be made clearer with the use of various

illustrations throughout this paper. As in 2007, it is estimated that the percentage of people 65 years or over will be $7.5 \%$ and come 2050 , the figure is projected to reach $16.1 \%$, which is a $115 \%$ increase in 43 years. On the contrary, between 1950 and 2007, the percentage of people $\geq 65$ years rose by only $2.2 \%$ (Table 1 ).

Table 1: Observed \& Forecasted percentage of elderly 65 years or over in selected regions, and the world countries: 1950, 1975, 2025 and 2050 .

\begin{tabular}{|c|c|c|c|c|c|}
\hline & $\mathbf{1 9 5 0}$ & $\mathbf{1 9 7 5}$ & $\mathbf{2 0 0 7}$ & $\mathbf{2 0 2 5}$ & $\mathbf{2 0 5 0}$ \\
\cline { 2 - 6 } & $\mathbf{\%}$ & $\mathbf{\%}$ & $\mathbf{\%}$ & $\mathbf{\%}$ & $\mathbf{\%}$ \\
\hline World & 5.2 & 5.7 & 7.5 & 4.2 & 16.1 \\
\hline Africa & 3.2 & 3.1 & 3.4 & 10.1 & 18.4 \\
\hline Latin America \& the Caribbean & 3.7 & 4.3 & 6.3 & 11.4 & 18.9 \\
\hline Caribbean & 4.5 & 5.4 & 7.8 & & \\
\hline
\end{tabular}




\begin{tabular}{|c|c|c|c|c|c|}
\hline China & 4.5 & 4.4 & 7.9 & 13.7 & 23.6 \\
\hline India & 3.3 & 3.8 & 5.4 & 8.1 & 14.8 \\
\hline Japan & 4.9 & 7.9 & 27.9 & 35.2 & 41.7 \\
\hline Europe & 8.2 & 11.4 & 16.1 & 21 & 27.6 \\
\hline Italy & 8.3 & 12 & 20.4 & 26.4 & 35.5 \\
\hline Germany & 9.7 & 14.8 & 19.6 & 23.9 & 25.4 \\
\hline Sweden & 10.3 & 15.1 & 17.6 & 22.1 & 24.7 \\
\hline USA & 8.3 & 10.5 & 12.4 & 17.7 & 20.6 \\
\hline \multicolumn{6}{|c|}{ Source: United Nations [1]. } \\
\hline
\end{tabular}

Table 2: Observed \& Forecasted Percentage of elderly 60 years or over in selected regions, and the world countries: 1950, 1975

2025 and 2050.

\begin{tabular}{|c|c|c|c|c|c|}
\hline & $\mathbf{1 9 5 0}$ & $\mathbf{1 9 7 5}$ & $\mathbf{2 0 0 7}$ & $\mathbf{2 0 2 5}$ & $\mathbf{2 0 5 0}$ \\
\cline { 2 - 6 } & $\mathbf{\%}$ & $\mathbf{\%}$ & $\mathbf{9}$ & $\mathbf{\%}$ & $\mathbf{\%}$ \\
\hline World & 8.2 & 8.6 & 10.7 & 15.1 & 21.7 \\
\hline Africa & 5.3 & 5 & 5.3 & 6.4 & 10 \\
\hline $\begin{array}{c}\text { Latin America \&the Carib- } \\
\text { bean }\end{array}$ & 6 & 6.5 & 9.1 & 14.5 & 24.1 \\
\hline Caribbean & 6.9 & 8.1 & 11.1 & 16.4 & 24.8 \\
\hline China & 7.5 & 6.9 & 11.4 & 20.1 & 31 \\
\hline India & 5.6 & 6.2 & 8.1 & 12 & 20.7 \\
\hline Japan & 7.7 & 11.4 & 27.9 & 35.2 & 41.7 \\
\hline Europe & 12.1 & 16.4 & 21.1 & 28 & 34.5 \\
\hline Italy & 12.2 & 17.4 & 26.4 & 34.4 & 41.3 \\
\hline Germany & 14.6 & 20.4 & 25.3 & 32.1 & 35 \\
\hline Sweden & 14.9 & 21 & 24.1 & 28.3 & 30.9 \\
\hline USA & 12.5 & 14.8 & 17.2 & 23.8 & 26.4 \\
\hline & & & & \\
\hline
\end{tabular}

Source: United Nations [1].

However, by 2030, [1] in every 8 (i.e. $12.5 \%$ of the globe's population) humans will be 65 years and older, and this is coming from $6.9 \%$ in 2000 . But there is a discourse as to whether or not 'old age' begins are 60 or 65 years; hence, we will present the figures as if we were using 60 years. Thus, if we are to use 60 years and older, the trends are relatively similar to those for ages 65 year or over. As in 1950, the world's population aged 60 years and older was 1 in 15 (8.2\%); but in 2007 (Table 2), the figure rose to 1 in 9 (10.7\%), and the projected 21.7 percent (or 1 in 5) by 2050 [1].

Based on percentages, the world's elderly population $(\geq 60$ years) between 1950 and 1975 increased by $0.4 \%$. However, between 1975 and 2007, the percentage of 'old people' rose by $2.1 \%$ but for 2025-2050, the increase is expected to be 6.6\%. Presently, China, United States, Germany, India, Sweden, Italy, and Japans have in excess of 50 percent of the world's population who are 65 years or older. But, does populating ageing stop with those societies only? The yardstick for measuring ageing population is having $8-10 \%$ of the population reaching at least 65 years. As of 2025, the Caribbean will have an estimated $11.4 \%$ of its population $\geq 65$ years. Statistics show that the percentage of Caribbean population $\geq 65$ years is more than for the combine Latin American the Caribbean. Since population ageing refers to changes in the entire age distribution, any single indicator might appear insufficient to measure it [2], which appears to have befallen many Caribbean states. This is evident in the political landscape of Caribbean nations as the issue of demographic ageing has not taken on as a serious issue as debt burden, inflation, unemployment, crime and international relations.

The rationale for this delay is embedded in perception that critical as this time. But this position is further from the truth. Because apart from the demographic transition that is taken place globally and equally within the Caribbean, there is another aspect to this phenomenon. As the implications of ageing range from pension schemes problems, higher health care costs and programmers. These do not cease there, as there are two important issues that we have yet to address, how we will be dealing with production and productivity within the context of an ageing nation ('shrinking labour force because of ageing'; 'possibly the bankruptcy of social security systems'). One media has written that two-thirds of people $\geq 65$ years are alive today [3], which strengthens the issue of taking population ageing to the forefront of national debate. Thus, it is clear that population ageing is global phenomenon; but is the extent of this in Caribbean states? To further comprehend this phenomenon or to explain this unbounded demographic reality; I will contextualize this paper within a global framework, with particular emphasis on selected Caribbean and more so on Jamaica.

\section{Ageing Defined}

Ageing is a significant but neglected dimension of social stratification and the life-course is an essential component of the analysis of status [4]. "Where 'Old age' begins is not precisely defined, the unset of older age is usually considered 60 or 65 years of age" [5]. The indecisiveness to reach consensus on a definition of ageing in spite the United Nations' perspective on the elderly, which is chronological ageing that begins at 60 years, yet demographers and many statisticians continue to conceptualize this variable as beginning at age 65 years [6-11]. This discourse will not be settled in this paper, but what will happen here is that the various perspectives will be presented to the readers. As a demographer, however, I will primarily be using the chronological age of 65 years and older to present the commencement of 'old age' (or ageing). But one should keep in mind as Turner outlines that ageing is a 'social stratification' which is neglected within the discourse of social stratification. 
In medieval times, Thane [12] notes that 'old age' were defined as 60 years and older. She justified this by forwarding an argument for the established age. In medieval England, men and women ceased at 60 years to be liable for compulsory service under labour laws or to participate in military duties. Ancient Rome, on the other hand, 'old age' began from early 40 to 70 years, with 60 years being "some sort of annusclimactorius". Demographers see the seniors the elderly or the aged (old people) - as individuals 65 years and older and not an individual who is 60 years of age. Western societies use 65 years and older to represent the elderly (seniors) as this is the period when people become fully eligible for Social Security benefits. Irrespective of the commencement age of the elderly, there is a wholesale agreement that the aged at the beginning of the next generation will be a real social challenge. One scholar emphasized that there is no absoluteness in the operational definition of the "elderly" [13]. She commended that from the World Assembly of Ageing (which was held in Vienna in 1982), the "elderly" is using the chronological age of 60 years and older 'as the beginning of the ageing process'. Jamaica having signed the Vienna Declaration of Ageing, which defines ageing to begin at 60years, Elder mire questioned academics and other scholars for their rationale in using 65 years. I will now classify the ageing in two main categories,

\section{A. Chronological \\ B. Biological ageing}

\section{Chronological ageing}

Within the study of demography, the elderly begins at the chronological age of 65 years - using the unit of analysis of time, based on the number of years and months that has elapsed since birth $[9,14,15]$. However, based on the monographs from other scholars [16-22], the issue of the aged begins at 60 years. Hence, the issue of the aged continues to battle from non- standardization. For those who use 60 years, they adopt this value because of the World Assembly on Ageing (in Vienna, Austria: July-August 1982), which forwards that ageing begins at the chronological of 60 years.

The Canadian statistical agency used age 65 years as the dividing line between "young" and "old" $[9,15,23]$. The issue of using the chronological age of 65 years to measure older adulthood according to one academia comes from the minimum age at which the Social Security System begins disbursing payment for pension to people living with the United States [14]. It is argued that in 1935 the U.S. government modeled this from the German's retirement system. This explains the use of 65 years of age by many scholar, practitioners and non-professionals ever since. This approach subdivides ageing into three categories. These are

A. Young-old (ages 65 through 74 years),

B. Old-old (ages 75-84 years) and oldest-old (ages 85 years and beyond). However, is there a difference between biological and chronological ageing?

\section{Biological ageing}

Organism aged naturally, which explains biological ageing. This approach emphasizes the longevity of the cells, in relation to the number of years the organism can live. Thus, in this construction, the human body (an organism) is valued based on physical appearance and/or state of the cells. Embedded in this apparatus is the genetic composition of the survivor. This occurs where the body's longevity is explained by genetic components. Gompertz's law in Gavrilov \& Gavrilova [24] shows that there is fundamental quantitative theory of ageing and mortality of certain species (the examples here are as follows - humans, human lice, rats mice, fruit flies, and flour beetles [25]. Gompertz's law went further to establish that human mortality increases twofold with every 8 years of an adult life, which means that ageing increases in geometric progression. This phenomenon means that human mortality increases with age of the human adult, but that this becomes less progress in advance ageing. Thus, biological ageing is a process where the human cells degenerate with years (i.e. the cells die with increasing in age), which is explored in evolutionary biology [26]. But studies have shown that using evolutionary theory for "late-life mortality plateaus", and fail because of the arguably the unrealistic set of assumptions that the theory uses to establish itself.

Reliability theory, on the other hand, is a better fitted explanation for the ageing of humans than that argued by Gompertz's law as the 'failing law' speaks to deterioration of human's organisms with age [24] as well as non-ageing term. The latter based on Gavrilov \& Gavrilova [2] can occur because of accidents and acute infection, which is called "extrinsic causes of death. While Gompertz's law speaks to mortality in ageing organism due to age-related degenerative illnesses such as heart diseases and cancers, a part of the reliability function is Gompertz's function as well as the nonageing component.

When the biological approach is used to measure ageing, this may be problematic as two different individuals with the same organs and physical appearance may not be able to perform at the same rates, which speaks to the difficulty in using this construct in measuring ageing. Nevertheless, this construct is able to compare and contrast organisms in relation to number of years, a cell may be likely to exist. Erber [14], argues that this is undoubtedly subjective, as we are unable within definiteness predict the life span of a living cell [14]. Interestingly, the biological approach highlights that the ageing process comes with changes in physical functioning. The oldest-old categorization is said to be the least physical functioning compared to the other classification in chronological ageing. The young-old, on the other hand, are more likely to be the most functioning as the organism is just beginning the transition into the aged arena [14,27].

In order to avoid such pitfalls in constructions that may arise with the use of the biological approach, ergo, for all intent and purposes, given the nature of policy implications in effective planning, the researcher is forwarding the perspective that seniority in age commences at age 65years-using the chronological ageing approach.

In summarizing the ageing transition, both chronological and biological ageing have a similar tenet. In that, as we move from young-old to oldest-old, the body deteriorates and what was of 
low severity in the earlier part of the ageing process becomes of critical mass in the latter stage. Hence, at the introductory stage of the ageing transition, the individual may feel the same as when he/ she was in the working age-population, but the reality is the body is in a declining mode. Because humans are continuously operating with negatives and positive, as he/she becomes older - using the ageing transition (i.e. 65 years and older)-the losses (or negatives) outweigh the positives. This simply means that the functionality limitation of the body falls, and so opens the person to a higher probability of becoming susceptible to morbidity and mortality. Secondly, the environment, which may not have been problematic in the past, now becomes a health hazard. One University of Chicago scholars summarizes this quite well in (Table 3).

Table 3: Characteristics of the Three Categories of Elderly, and Ageing transition

\begin{tabular}{|c|c|c|c|}
\hline \multirow{2}{*}{ Characteristic } & \multicolumn{3}{|c|}{ The Ageing Transition } \\
\cline { 2 - 4 } & Young-old & Aged & Oldest-old \\
\hline Heath problems & Low & Moderate & High \\
\hline Physical disability & Low & Moderate & High \\
\hline Demand for medical care & Low & Moderate & High \\
\hline Demand for public service & Low & Moderate & High \\
\hline Demands on children & Low & Moderate & High \\
\hline Dependency on other & Low & Moderate & High \\
\hline Social isolation & Low & Moderate & High \\
\hline
\end{tabular}

Source: This is taken from Essays in Human Ecology Bogue [28]

\section{Historical Issues on Population Ageing: Global Perspectives}

Ageing has emerged as a global phenomenon in the wake of the now virtually universal decline in fertility and, to a lesser extent, of increases in life expectancy [28]. In the earlier centuries, pandemic and pestilence would destroy millions of lives. An example here is, in the fourteenth century, the 'Black Death', killed approximately 40 million people worldwide. One scholar argues that this disease 'wiped out' about one-third to one-half of European's and Asian's human population [29]. As during the 1700s, smallpox killed an estimated 100 peoples worldwide. This reality explains why population ageing was not a phenomenon then, as the deaths were high and widespread. Therefore, the person was not likely to live beyond fifty years. Following those pandemics and plagues, the discoveries of peninsulin along with proper sanitation and public health have seen a significant reduction in mortality. Whereas low mortality is not synonymous with all nations, low death rates have been the experience of a plethora of the developed societies. This reality is also happening in many developing and emerging nations. Accompanying mortality decline is the issue of the fertility transition that began in the France in the $19^{\text {th }}$ century. It is argued, that reduction is fertility is primarily a cause of population ageing today as well as steady decline in mortality rates.
Even though, the ageing process is lifelong and though this may be constructed within each society differently, many decades have elapsed since Galton's study on the health status of people. Despite changes in human development and the shifts in world population toward demographic ageing - people living beyond 65 years [30,31], the issues of the aged and their health status, in particular general wellbeing, have not taken front stage on the radar of demographers unlike many other demographic issues.

The $20^{\text {th }}$ century has brought with it massive changes in typologies of diseases where deaths have shifted from infectious diseases such as tuberculosis, pneumonia, yellow fever, Black Death (i.e. Bubonic Plague), smallpox and 'diphtheria' to diseases such as cancers, heart illnesses, and diabetes. Although diseases have shifted from infectious to degenerate, chronic non-communicable illnesses have arisen and are still lingering within all the advances in science, medicine and technology. One demographer showing the extent of human destruction due to the Black Death mentioned that this plague reduced Europe's population by one-quarter [29]. Accompanying this period of the 'age of degenerative and manmade illnesses' is life expectancies that now exceed 50 years. So, while people aged 70 years and beyond in many developed and a few developing states, the question is - Are they living a healthier life - how is their wellbeing within the increases in life expectancy? Alternatively, is it that we are just stuck on life expectancies and diseases as primary predictors of wellbeing - or health status?

Before the establishments of the American Gerontology Association in the 1930s and their many scientific studies on the ageing process [14], many studies were done based on the biomedical model (i.e. physical functioning or illness and/or disease-causing organism) [27]. Many official publications used either

\section{A. Reported illnesses and ailments}

B. Prevalence of seeking medical care for sicknesses.

Some scholars have still not move to the post biomedical predictors of health status. The dominance of this approach is so strong and present within the twenty first century, that many doctors are still treating illnesses and sicknesses without an understanding of the psychosocial and economic conditions of their patients. To illustrate this more vividly, the researcher will quote a sentiment made by a medical doctor in The Caribbean Food and Nutrition Institute Quarterly, 1999. A public health nutritionist, Dr. Kornelia Buzina, says that "when used appropriately, drugs may be the single most important intervention in the care of an older patient and may even endanger the health of an older patient $[32,33]$.

A demographer, Alain Marcoux, measured population ageing in an article titled 'Population ageing in developing societies: How urgent are the issues?' as a specified valuation of the general population being 60 years and older. The benchmark that was used to establish this situation is the proportion of the population who is aged 60 years and over exceeds 10\% [16] whereas another group of scholars Gavrilov \& Heuveline [2] used 65 years and beyond that 
exceeds 8-10\%. These include for example - Germany, Greece, Italy, Bulgaria and Japan; USA; Sweden [34]. Interestingly, Greece and Italy's aged population (people 60 years and older) in 2000 stood at least $24 \%$ of the total population [35], which indicate completion of the fertility and mortality transition, and the high burden being placed on the working population. Those societies' fertility decline began early and their mortality at older ages has been declining; this justifies their ageing population. This is not only confined to developed societies as it is spreading to the entire world.

\section{Demographic Trends: The Global perspective}

Globally, trends in population ageing are such that demographic ageing is seen as a fundamental phenomenon of concern both inside and outside of the intelligentsia class. I will display the issue in great details below, as the figures will speak of the trends that we have seen more so since the 1900s. And that this progression will continue in the next 50 years. The age persons $>65$ years and older in 1950 was $5.2 \%$, and by 1995 the figure rose to $6.5 \%$. But, during the $1950 \mathrm{~s}-1960 \mathrm{~s}$, the $65+$ age cohort rose by $0.1 \%$ (Table 4 ), which may be marginal, but it earmarks the beginning a demographic phenomenon.

Table 4: Percentage world population estimates of aged persons 65 yrs and older.

\begin{tabular}{|c|c|c|c|}
\hline Year & Percentage & Year & Percentage \\
\hline 1950 & 5.2 & & \\
\hline 1955 & 5.3 & 2005 & 7.4 \\
\hline 1960 & 5.3 & 2010 & 7.6 \\
\hline 1965 & 5.3 & 2015 & 8.2 \\
\hline 1970 & 5.5 & 2020 & 9.1 \\
\hline 1975 & 5.7 & 2025 & 10 \\
\hline 1980 & 5.9 & 2030 & 11 \\
\hline 1985 & 5.9 & 2035 & 12 \\
\hline 1990 & 6.2 & 2040 & 12.8 \\
\hline 1995 & 6.5 & 2045 & 13.3 \\
\hline 2000 & 6.9 & 2050 & $16.1^{*}$ \\
\hline \multicolumn{2}{|c|}{ Source: United Nations [1] 2005; United Nations, 2007:72 } \\
\hline
\end{tabular}

In 1999, persons aged 65 and older were 410.5 million, and one year later the figure rose to 420 million, which is a 2.3 percentage increase over the previous year. And during 2000 to 2030 , it is estimated that aged person $>65$ years, will rise from an approximated 550 million to a projected 973 million (i.e. $76.9 \%$ ). By 2050 , the persons aged 65 years and beyond, will be some $13.8 \%$ of the world's population. Currently, the developed nations share disproportionately more of the aged persons $>65$ years, this is not projected to change in the future. However, by 2030, the absolute number of aged $>65$ years in the developing societies is expected to triple, which will not be the same for the developed nations (i.e. from 249 million in 2000 to 690 million by 2030). In summary, during 1950-2000, the elderly population (i.e. persons $65+$ ) increased by $1.7 \%$. However, from $2000-2050$, the same aged cohort will rise by $6.9 \%$, which denotes a $100 \%$ increase in 50 years.
The statistics reveal that come 2050 most of the aged population will be residing in developing countries. In addition, by 2030 the population 65-and older in developing societies would have increased by 140 percent, which is $40 \%$ more elderly in developing nations than in the world. Importantly, the aged are on the upper end of the ageing spectrum; and this affects the population dynamics [2] of the society. The total human population, within any geographic area, constitutes children, youth, working aged people and the elderly. With this said, the "graying" of a population is caused by fertility decline, reduced mortality and migration of the young and return of retirees coupled with increases in life expectancies. Where the elderly population out grows the younger population, this constricts the population structure at younger ages and expanding it at older ages [29]. This is referred to as demographic transition [3]. It is the experienced of many developed countries that started with France, but it has increasingly become a phenomenon for many developing nations.

The demographic development of the world is not limited to the increase in persons 65 years and older but their education children population (persons0-14years). In 1950, the children population was $34.3 \%$ of the globe's population, and in 1975 the figure rose to $36.8 \%$, and in 2007 the United Nations [1] writes that this is expected to be $27.6 \%$ and come $2050,20.2 \%$. Accompanying this reduction in the children population is the increase in the median age of the world's population [4]. As at the state of the1950, this was 23.9 years, it fell to 22.4 years in 1975 and is estimated to rise to 28.1 years in 2007 and project to reach 37.8 years, which is an indication of population ageing. The increase in proportion of people $\geq 65$ and changes in the median age can be simply explained by mortality changes, which demographers use life expectancy to explain. In life expectancy at birth during $1950-1955$ was $46.6 \%$, in 1975- 1980, 59.9 years, and 2005-2010, 66.5 years and come 20452050 it is expected to reach 75.1 years.

In the more developed nations, currently (in 2007) estimated by the United Nations, 2007:74), 20.7\% of the population are persons $\geq 60$ years, $15.5 \%$ are persons $\geq 65$ years, and $3.9 \%$ are persons $\geq 80$ years. The life expectancy for people in these regions is more than the world's figure, as the United Nations [1] writes that during 2005-2010, it is 76.2 years. However, in Northern Europe, it is 78.7 years, Southern Europe; it is 79.1 years, Western Europe, 79.6 years, and in Northern America, 78.2 years. Thus, population ageing is indeed a global phenomenon and more so in developed nations, but what about the Caribbean and in particular Jamaica?

\section{Demographic Trends: Selected Caribbean Nations}

Ageing inevitable means longer life, that affects the population composition and structure. In that as the population ages, the base of the population pyramid narrows, while the upper portion expands. Demographers argue that this is substantially due to fertility transition and reduced mortality at older ages. If reduced fertility continues without any major catastrophe in the future, what we are likely to experience is people living longer, and the death rates at older ages will begin to naturally increase thereby changing the population age structure further. Global life expectancy has risen 
from 47 years in 1950-1955 to 65 years and beyond in 2000-2005 and 2005-2015, which is similar for Jamaica, Trinidad and Tobago, Bahamas and Barbados [36-38]. One of the probabilistic results of age in register educational the working aged and they outfall populations.

These provide shifts in the population pyramid as it contracts at younger ages and expand at older ages. This is reiterated in a publication of the Caribbean Food and Nutrition Institute [32] that stated, "By the year 2050, there will be older persons than children in the world, the majority of whom will be females and widowed or without a partner. The Caribbean is likely to mirror this phenomenon..." [32]. The Statistical Institute of Jamaica pointed out that those societies that were at the early stage of the demographic transition in which fertility remains high and mortality decline are now experiencing increasing in younger population. However, for those that at the late stage, where fertility is declining, and mortality is stationary, the younger sector of the population is smaller than the segment 60 years and older [39,40]. This is in keeping with the global perspective on demographic transition.
Demographic development in the Caribbean has taken a similar path like the rest of the world [36,41-43]. Over the years, the movement as being such that mortality and fertility has been declining, and the population 65 years and older has been increasing proportionately more than proportion who are children (Table 5 \& 6).

Table 5: Percentage of caribbean's aged persons 65 years (yrs) and older, children: 1950-2050.

\begin{tabular}{|c|c|c|c|}
\hline \multicolumn{2}{|c|}{ Elderly (65+ yrs.) } & \multicolumn{2}{c|}{ Children (0-14 yrs.) } \\
\hline Year & Percentage & Year & Percentage \\
\hline 1950 & 4.5 & 1950 & 38.6 \\
\hline 1975 & 5.4 & 1975 & 39.9 \\
\hline 2007 & 7.8 & 2007 & 27.1 \\
\hline 2025 & 11.4 & 2025 & 23 \\
\hline 2050 & 18.9 & 2050 & 18.6 \\
\hline \multicolumn{3}{|c|}{ Source: World Population Ageing [1]: 114-115. } \\
\hline
\end{tabular}

Table 6: Percentage of estimated or projected populations of selected Caribbean Nations, 1980, 2000, 2005 and 2020.

\begin{tabular}{|c|c|c|c|c|c|c|c|c|}
\hline \multirow{2}{*}{ Country } & \multicolumn{2}{|c|}{1980} & \multicolumn{2}{|c|}{2000} & \multicolumn{2}{|c|}{2005} & \multicolumn{2}{|c|}{2020} \\
\hline & $0-14$ yrs & $60+y r s$ & $0-14$ yrs & $60+y r s$ & $0-14$ yrs & $60+y r s$ & 0-14 yrs & $60+y r s$ \\
\hline Barbados & 29.6 & 14.1 & 22.5 & 14.1 & 18.9 & 13.2 & 19.4 & 19.3 \\
\hline Guyana & 40.9 & 5.7 & 30.2 & 6.3 & 29.4 & 7.4 & 23 & 11.3 \\
\hline Jamaica & 40.3 & 9.3 & 28.3 & 9 & 31.2 & 10.2 & 20.4 & 12.4 \\
\hline Suriname & 39.8 & 6.3 & 32.4 & 7.9 & 30.1 & 9 & 24.2 & 9.8 \\
\hline Trinidad \& Tobago & 34.3 & 8.1 & 28.6 & 8.4 & 21.5 & 10.7 & 23.5 & 13.3 \\
\hline Caribbean & 36.7 & 8.6 & 29.9 & 9.9 & 27.7 & 10.7 & 24.2 & 14.2 \\
\hline
\end{tabular}

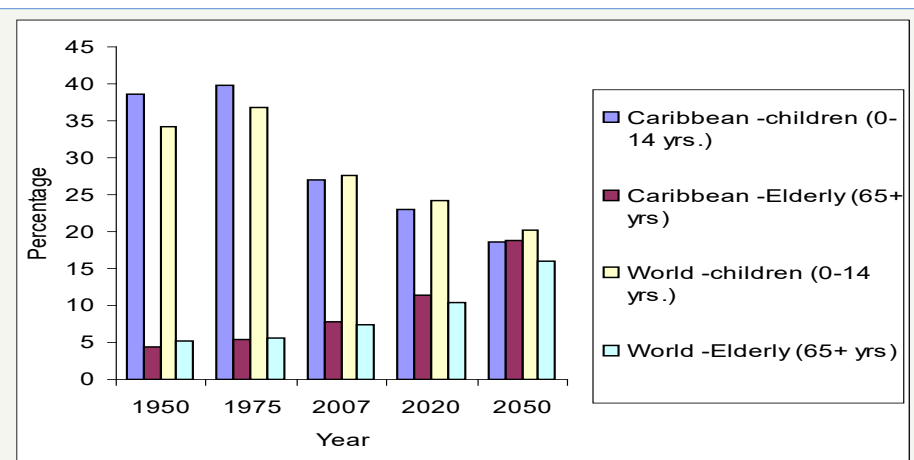

Figure 1: Proportion of children and elderly population of the caribbean and the world: 1950-2050.

I will present a graphical display of the populations of the World and the Caribbean of two age cohorts, children (0-14years) and elderly (65+), as an indication of the similarities these demographic trends (Figure 1). A further subdivision of selected Caribbean nations' proportion of children and elderly populations are presented in (Table 6). By the standard that if a population of aged person using $\geq 60$ years exceeds $8-10 \%$ of the population, there is the issue of demographic ageing. So, since 1980, countries like Barbados, Jamaica, Trinidad and Tobago and generally the Caribbean have been experiencing this phenomenon (Table 6).
From the Table, by 2020, Barbados' elderly population will be higher than that of the Caribbean's average. Among the factors of population ageing are mortality and fertility. Thus, merely using the proportion of persons who are either $65+$ or $0-14$ years is an indicator of demographic transition, but mortality and fertility are critical determinants of ageing population. According to the United Nations [1], decreasing fertility has been the primary cause of population ageing because, as fertility moves steadily to lower levels, people of reproductive age have fewer children relative to those of older generations, with the result that sustained fertility 
reductions eventually lead to reduction of the proportion of children and young persons in a population and a corresponding increase of the proportion in older groups [1].

The United Nations' perspective has highlighted the importance of including fertility in demographic transition discourse as well as mortality. Statistics reveal that the total fertility rate (TFR) for 1970-1975 for the world was 4.49 and for 2000-2005, it fell to 2.65; whereas in Latin America and the Caribbean between 1970-1975, it was 5.05 and this was further reduced to 2.55 in 2000-2005 [36]. Concurrently, in 2005, total fertility in The Bahamas is 2.2, in Barbados it is 1.5, for Jamaica 2.3 and for Trinidad and Tobago, 1.6 [37]. Barbados and the twin islands of Trinidad and Tobago are experiencing below replacement level fertility (Total Fertility Rate - TFR of 2.1 - United Nations 2000, 4), a problem presently faced by many developed nations such as those in Southern and Easter Europe and the United States [36]. I have presented (Table 7), for a more detailed assessment of the total fertility trends of selected Caribbean States, the Caribbean and Latin America, in an effort for us to see the trend in this phenomenon, and the implications of this for population ageing come 2050.

Table 7: Total fertility rate for selected caribbean nations, Caribbean, and Latin American: 1950-1955 to 2045-2050.

\begin{tabular}{|c|c|c|c|c|c|}
\hline Countries & 1950-1955 & $1975-1980$ & $2005-2010$ & $2025-2030$ & 2045-2050 \\
\hline Bahamas & 4.1 & 3.2 & 2.2 & 1.9 & 1.9 \\
\hline Barbados & 4.7 & 2.2 & 1.5 & 1.8 & 1.9 \\
\hline Belize & 6.7 & 6.2 & 2.8 & 2 & 1.9 \\
\hline Dominican Rep & 7.4 & 4.7 & 2.6 & 2.1 & 1.9 \\
\hline Guyana & 6.7 & 3.9 & 2.1 & 1.9 & 1.9 \\
\hline Haiti & 6.3 & 6 & 3.6 & 2.5 & 2.1 \\
\hline Jamaica & 4.2 & 4 & 2.3 & 2 & 1.9 \\
\hline Suriname & 6.6 & 4.2 & 2.4 & 2 & 1.9 \\
\hline Trinidad \& Tobago & 5.3 & 3.4 & 1.6 & 1.8 & 1.9 \\
\hline Caribbean & 5.2 & 3.6 & 2.4 & 2.1 & 1.9 \\
\hline Latin America \& Caribbean & 5.9 & 4.5 & 2.4 & 2 & 1.9 \\
\hline Source: World Population Ageing [1] & & & & & \\
\hline
\end{tabular}

Table 8: Life Expectancy at birth of both sexes for selected caribbean nations, the Caribbean, and Latin American.

\begin{tabular}{|c|c|c|c|c|c|}
\hline Countries & $1950-1955$ & $1975-1980$ & 2005-2010 & 2025-2030 & $2045-2050$ \\
\hline Bahamas & 59.8 & 67.2 & 72.1 & 78 & 82 \\
\hline Barbados & 57.5 & 71.4 & 76.4 & 79.2 & 81.4 \\
\hline Belize & 57.7 & 69.7 & 71.7 & 74 & 78 \\
\hline Dominican Rep & 45.9 & 61.9 & 68.6 & 73.8 & 77.7 \\
\hline Guyana & 52.3 & 60.7 & 65.4 & 70.6 & 74.2 \\
\hline Haiti & 37.6 & 50.6 & 53.5 & 62.2 & 70.1 \\
\hline Jamaica & 55.8 & 70.1 & 71.1 & 75 & 77.7 \\
\hline Suriname & 56 & 65.1 & 70.2 & 74.7 & 78.1 \\
\hline Trinidad \& & 59 & 68.3 & 70.1 & 74.1 & 78.5 \\
\hline \multicolumn{6}{|l|}{ Tobago } \\
\hline Caribbean & 52.2 & 64.5 & 68.7 & 73.2 & 76.9 \\
\hline Latin America \& Caribbean & 51.4 & 63 & 72.9 & 76.8 & 79.5 \\
\hline \multicolumn{6}{|c|}{ Source: World Population Ageing [1] } \\
\hline
\end{tabular}

Another determinant of the demographic transition is mortality. The mortality statistics are used to compute the life expectancies, and so I will use the latter as it is an indicator of the former. Mortality in the Caribbean has been falling and this can be seeing from the increased life expectancies, which are highly comparable with those in developed nations, which is beyond 71 years [1] (Table 8).

\section{Demographic Trends: Jamaica}

The use of life expectancy, mortality, and total fertility rates are just some of the ways with which demographic development can be shown. Instead of show both mortality and life expectancy, for this section of the paper I will use life expectancy. As mortality rates 
are used to calculate the life expectancy at various ages (Table 9). Another way of depicting population changes is through the use of a population pyramid. In this section, I will use Jamaica's population pyramid since 2000 to depict the demographic transition occurring in this society, and then percentages of the elderly people with regard to the total population. It should be noted that the nation's population pyramid in the 2000 showed a narrow top and a broad base. But by 2025 , the population narrows at the base and begins to expand at the middle, and come 2050 , the note how the population contrast at the base as we move toward an ageing population (Figure 2).

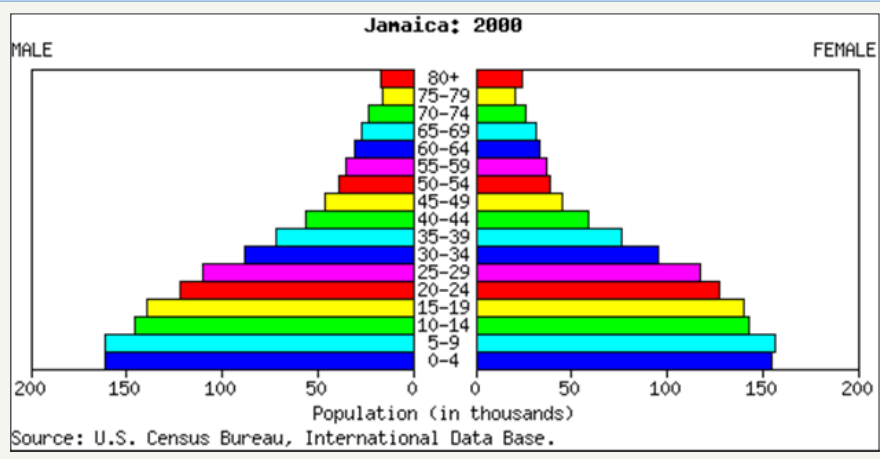

Figure 2: Population pyramid of Jamaica, 2000.

From the US Census Bureau, International Data Base, Jamaica's population in 2000 showed a relatively young population, which is because of the broad base. This triangular age profile is an indication of the high proportion of children, which means that Jamaica in 2000 had a high fertility and high mortality. However, the young population that was observed in 2000 from all indication is shifting as the base of the age profile narrows and the middle expands. Within the demographic transition, this is a representation where the young population is falling and shifting toward the middle ages, and old type of profile.

While the demographic transition is not necessarily obvious in the 2025, Jamaica's age type population profile will definitely be contracting at the base and expanding at middle and old ages. Such a profile denotes is as indication of low fertility and death rates. A careful look at the diagram reveals that the come 2050 and beyond, Jamaica's oldest elderly will substantially more females. The "graying" of the Jamaica's population is coming, and has already made its way within the society [44]. From a demographic perspective, relatively speaking a society is said to be old whenever the population of person aged 60 or over (and some scholars use 65 years or over) exceeds $8-10 \%$, which is the case in Jamaica (Figure 3 ). This is not the only indicator as life expectancy can be used to show population ageing. Jamaica's life expectancy at birth for males between 1879 and 1882 was 37.02 years and for females it was 39.80 years, between 2002 and 2004 males' life expectancy rose to 71.26 years and that of the females to 77.07 years, which is a clear indictor of demographic ageing (Table 9).

Table 9: Life expectancy at birth of Jamaicans by sex, 1880-2004.

\begin{tabular}{|c|c|c|}
\hline \multicolumn{3}{|c|}{ Average Expected Years of Life at Birth } \\
\hline Period & Male & Female \\
\hline $1880-1882$ & 37.02 & 39.8 \\
\hline $1890-1892$ & 36.74 & 38.3 \\
\hline $1910-1912$ & 39.04 & 41.41 \\
\hline $1920-1922$ & 35.89 & 38.2 \\
\hline $1945-1947$ & 51.25 & 54.58 \\
\hline $1950-1952$ & 55.73 & 58.89 \\
\hline $1959-1961$ & 62.65 & 66.63 \\
\hline $1969-1970$ & 66.7 & 70.2 \\
\hline $1979-1981$ & 69.03 & 72.37 \\
\hline $1989-1991$ & 69.97 & 72.64 \\
\hline $1999-2001$ & 70.94 & 75.58 \\
\hline $2002-2004$ & 71.26 & 77.07 \\
\hline \multicolumn{2}{|l|}{ Sources: Demographic Statistics (1972-2006) } \\
\hline \multicolumn{2}{|l}{} \\
\hline
\end{tabular}

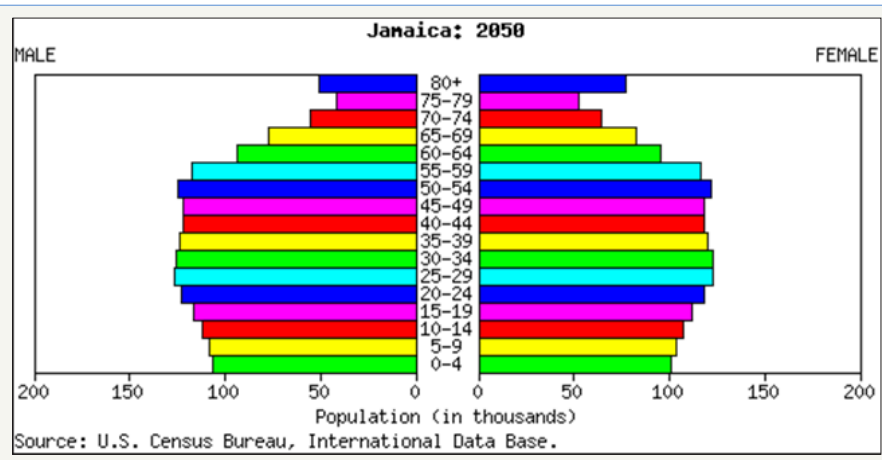

Figure 3: Population pyramid of Jamaica, 2025. 
From records of the Population Division of the United Nations, Jamaica's population 60 years and older in 2050, using the medium variant, is likely to be $24 \%$ of the entire population, with $18.1 \%$ being 65 years and older, compared to approximately $5 \%$ being $80+$ years. These shifts mean more degenerated conditions at older ages, increased disability and diminished quality of life. The disparity in gender composition speaks to the higher morbidity in women and higher mortality for men.

In 2004, Jamaica's old-age population stood at 7.7 percent. This is not atypical; according to WHO/SEARC [45], India's elderly population was 7.7 percent. During 2004-1991, the elderly population of Jamaica rose by 3.28 percent. When the elderly is strictly operational zed within a demographer's space (65 years and beyond), on an average the elderly population grew by 3.62 percent. The data reveal that for every 100 working-aged of the population there are approximately 13 elderly that is dependent on them. This is within approximately 30 percent of the population being children. Over the same period, the number of child-to-totalpopulation grew by-4.4 percentandby-10.08percent for the youth Within this context, there is a need to analyze the labour force participation of aged Jamaicans as there would be socio-economic implications if this were to be declining in the nation.

Table 10: Jamaica: Selected demographic variables, labour force participation (in \%).

\begin{tabular}{|c|c|c|c|c|c|}
\hline Total (\% of Population ${ }^{4}$ ) & 1950 & 1975 & 2007 & 2025 & 2050 \\
\hline $60+$ & 5.8 & 8.5 & 10.3 & 15 & 23.6 \\
\hline $65+$ & 3.9 & 5.8 & 7.6 & 10.3 & 17.7 \\
\hline $80+$ & 0.2 & 0.8 & 2 & 2.3 & 5.6 \\
\hline Female & 1950 & 1975 & 2007 & 2025 & 2050 \\
\hline $60+$ & 6.6 & 9 & 10.7 & 16.1 & 25.9 \\
\hline $65+$ & 4.4 & 6.3 & 8.1 & 11 & 19.9 \\
\hline $80+$ & 0.3 & 1 & 2.2 & 2.6 & 6.9 \\
\hline Male & 1950 & 1975 & 2007 & 2025 & 2050 \\
\hline $60+$ & 5 & 8 & 9.9 & 13.8 & 21.3 \\
\hline $65+$ & 3.2 & 5.3 & 7.1 & 9.7 & 15.4 \\
\hline $80+$ & 0.2 & 0.6 & 1.8 & 2 & 4.3 \\
\hline \multirow{2}{*}{ Median age } & 1950 & 1975 & 2007 & 2025 & 2050 \\
\hline & 22.2 & 17 & 24.9 & 30.7 & 39.3 \\
\hline $\begin{array}{c}\text { Labour Force Participa- } \\
\text { tion }\end{array}$ & 1980 & 1990 & 2007 & 2010 & 2020 \\
\hline $65+$ & 46.4 & 37.1 & 26.6 & 26.6 & 25.1 \\
\hline $65+$ & 30.4 & 23.6 & 13.8 & 13.1 & 12.3 \\
\hline $65+$ & 65.3 & 53.6 & 41.4 & 40.7 & 39.6 \\
\hline \multicolumn{6}{|c|}{ United Nations, 2007: 308-309 } \\
\hline
\end{tabular}

There is little debate within the public arena about the increasing decline of the labour force participation rate of aged Jamaicans. In 1980, the labour force participation rate (in \%) was $46.4 \%$ and it is estimated that this to be $26.6 \%$ in 2007 . This represents a $43 \%$ reduction in the number of aged person's $\geq 65$ years who were actively involved in the labour force. When the labour force participation rate is decomposed by sexes, the figures reveal a more telling disparity. As for females, in 1980, there were $30.4 \%$ of women actively involved within the labour force, but it is estimated to be $13.8 \%$ in 2007 , which is a $55 \%$ reduction in the number of employed females. With respect to males' involvement in the labour force, it is projected to fall to $41.4 \%$ in 2007 , which is coming from $65.3 \%$ in 1980 . The labour force participation rate for men will fall by $23 \%$ compared to that of females that will decline by $55 \%$. This is within the context of females living longer than their male counterparts, and that the retirement age for females is 60 years and not 65 years (Table 10). Therefore, if we are to extrapolate a reduced 5 years for females, the labour force participation rate will increase further by at least a percentage point.

Another variable that can be used to indicate population ageing is the median age. The median age denotes a value that where onehalf of the population is above or below that age. Continuing, the median age for Jamaica's populace in 1950 was 22.2 years and it is estimated to reach 24.9 years in 2007 and come 202531 years, and by 2050 it should increase by another 8.6 years. It should be note here, that demographers use a median age of 30 years to indicate an ageing population. Thus, population ageing is without a doubt a Jamaican phenomenon like the National debt problem and other social issues such as crime and teenage pregnancy.

Without effective population planning for the elderly, come the next four decades, the old-age population will become a burden to the working aged-populace in respect to medical care, nursing care, pension, other social insurance and survivability cost. With this impending social reality, there is a high probability that the old-aged will be called on to provide increasingly more of their needs for themselves within the construct limited resources from developing societies. The physiological changes with ageing such as loss of hair, wrinkling of the skin, decrease in height, and loss of teeth are not the only issue of old age but other critical factors that affect their wellbeing, which goes to the crux of protecting the rights of the elder [46].

\section{State of the Elderly, With Emphasis on Caribbean and Jamaica}

The Caribbean like many developed countries is now faced with the daunting task of addressing the "graying" of its population, because of mortality and fertility decline, which began in the 1960s. To show that this is a challenge to geographic topography, the region launched its first forum titled 'The Caribbean Symposium on Population Ageing' in November 2004 in Port of Span, Trinidad and Tobago, in order to strategize about this inevitable demographic transition, which began in earnest in developed societies. This is a precursor to its predecessor which was held in Vienna in 1982 called 'The First Assembly on Ageing' and another named' Second World Assembly on Ageing', which was in Madridin2002.

Like the developed world, the Caribbean islands are cognizant that policy implementation and mechanism are needed to forge an equitable solution for this phenomenon. With the Symposium comes 
the recognition that ageing is not limited to its call but that it affects the general society, future generations and political decisions. Ergo, what is the state of the grayed population in Caribbean and more so within Jamaica.

A study reveals that there is a statistical causal relationship between socioeconomic conditions and the health status of Barbadians. The findings reveal that $5.2 \%$ of the variation in reported health status was explained by the traditional determinants of health. Furthermore, when this was controlled for current experiences, this percent fell to $3.2 \%$ (falling by $2 \%$ ). When the current set of socioeconomic conditions were used they account for some $4.1 \%$ of the variation in health status, while $7.1 \%$ were due to lifestyle practices compared to $33.5 \%$ that was as a result of current diseases [47]. It holds that importance place by medical practitioners on the current illnesses - as an indicator of health status - is not unfounded as people place more value on biomedical conditions as responsible for their current health status. Despite this fact, it is obvious from the data - using 33.5\% - that there are other indicators that explain some $67.5 \%$ of the reason why health status is as it is.

Furthermore, with an odds ratio of 0.55 for number of illness, there is clearly suggesting that the more people reported illness, the lower will be their health status [47]. and this was equally so for more disease symptoms - odds ratio was0.71)Accompanying the reduction in physical functioning which is a feature of biological ageing [14] is the fact that the Jamaican elderly spend the most number of days receiving medical care for illnesses and/or injuries. In addition, they experience the highest rate of protracted illness the country, with the "... very young and the elderly being the most vulnerable" [48]. Embedded in this finding is the poor health status of the elderly despite living longer. Essentially, this particular group is suffering from ill health caused by diabetes, stress, psychiatric disorder and chronic diseases, which translates into lower quality of life while their life is prolonged [49,50], which means they are living longer but suffer more - the cost of longevity.

A Ministry of Health (MOH) report notes that the prevalence of chronic illnesses has also increased with ageing and that this is even more pronounced for those 65 years and older, with more males than females spending more time in health care facility [51], using the discharge rate - 975.1 per 10,000 for males compared to 817.1 per 10,000 females. Interestingly, when a detailed analysis was done of the data, seniors who reside in rural areas were suffering

Figure 4: Population pyramid of Jamaica, 2050

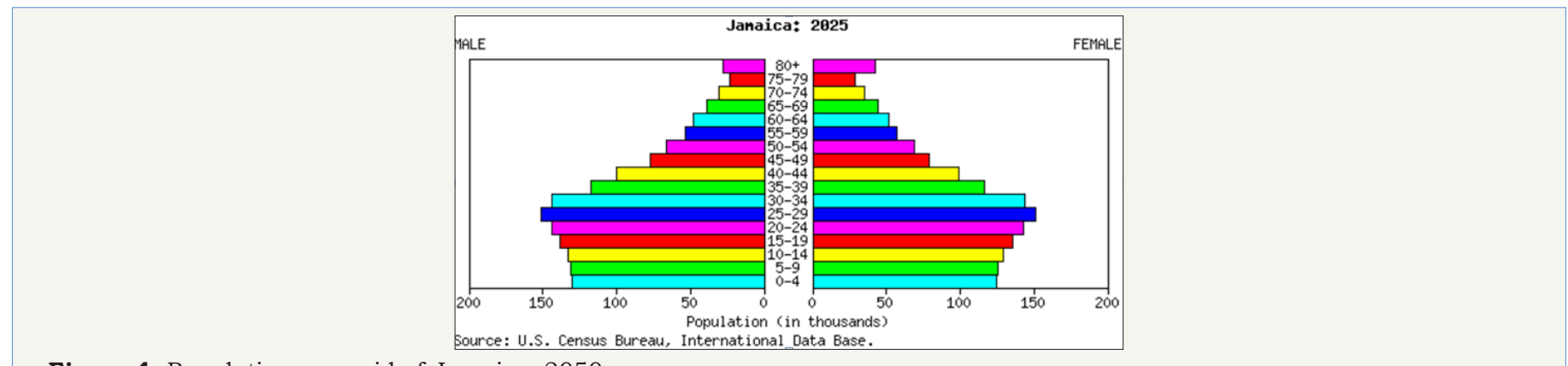

more than their counterparts who live in other zones [52]. The report summarizes the wellbeing status of those 60 years and older, when they say "... our 60 year olds exhibited the highest prevalence of protracted illness/injuries" The situation is speaks a state of well-being for the elderly that is not in keeping with the positives of the advancement in medicine and medical technology. There is definitely a disparity between the seniors' wellbeing reality and their lived years, which reiterates the need to measure wellbeing outside of the traditional biomedical model.

From the findings of a cross-sectional study conducted by Powell, Bourne \& Waller [53] of some 1,338 Jamaicans, $19.0 \%$ of respondents perceived that their economic well-being to be 'very bad'. In addition, when they asked, "Does your salary and the total of your family's salary allow you to satisfactorily cover your needs", $57.4 \%$ of them felt that this "does not cover" their expenses [53] What is the situation on the elderly seeing that this group is even more (or equally) vulnerable than other age cohorts? The answer to this is embedded within JSLC reports. The JSLC (1997) makes it clear that the aged population (22.6\%) and the children (less than five years - $14.7 \%$ ) reported the highest number of illness/injury, with those who resided in the rural areas being more vulnerable than those in other zones are. In order to capture the severity of the issues faced by the Jamaican aged, if we are to convert the mean number of days of reported illnesses into monetary terms, then the medical expenditure of the elderly would have helped to erode their well-being, along with the illnesses and their severity. Then, when retirement, loss of income, the cost associated with protracted ailments, and the psychological challenges associated with ageing are included in the daily life of the elderly, within the context of a shrinking economy, rising prices, the poor and the elderly in particular the poor aged would be more vulnerable than other age groups within this society.

There is an interconnection between economics and demography. In that, economists are concerned about human economic decisions at the micro and the macro level. The demographer, on the other hand, invests time in studying the science of human population. Therefore, while the demographer is not interested in the costing of decisions, the economist requires a thorough understanding of the principles of the human population, in an effort to effective comprehend how people within a particular geographic area are probable able to make decision. The interconnectivity is evident that at the London School of Economics, the department of demography is one subsection with the school. 
A study on the elderly published in the Caribbean Food and Nutrition Institute's [32] magazine Cajanus found that $70 \%$ of individuals who were patients within different typologies of health services were senior citizens [32]. Among the many issues that the research reported on are the six major causes of morbidity and mortality identified by the Caribbean Epidemiology Centre that is of paramount importance to this discussion. The influence ofcerebrovascular, cardiovascular, neoplasm, diabetes, hypertension and acute respiratory infection (Figure 4). The diagram below depicts the ranked order of the five leading causes of death for people 65 and over of selected Caribbean countries in1990.

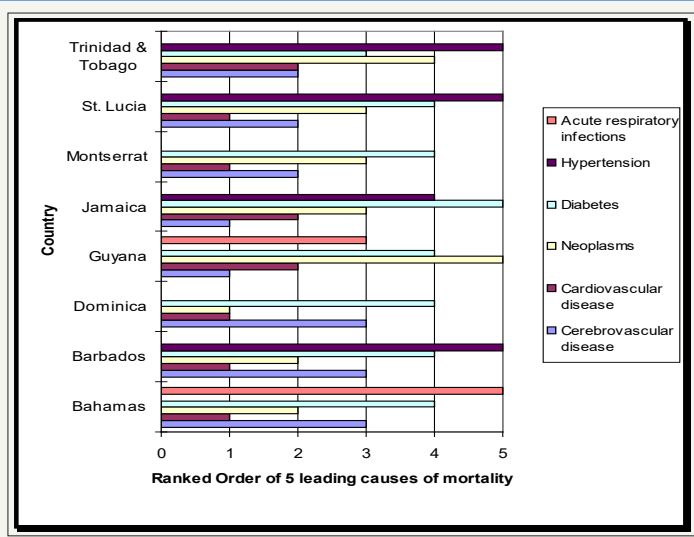

Figure 5: Ranked Order of the five leading causes of mortality in the population 65years and older, 1990 Source: adopted from Caribbean Food and Nutrition Institute [32]: 222.

In seeking to explain severity of the health status of Caribbean national, using Barbados and Jamaica, Caribbean Food and Nutrition Institute [32] presents the 5-leading causes of morbidity as reported by seniors. The data reveal that the primary cause of illnesses in Barbados and Jamaica was hypertension. In both countries, hypertension was a female phenomenon-in Barbados, females reporting $44.6 \%$ compared to $33.1 \%$ for males and in Jamaica it was $55.4 \%$ for females and $30.3 \%$ of males (Figure 5).

The data in (Figure 6) shows that hypertension and arthritis are morbidities that significantly plague both men and women in both Caribbean countries. These chronic non-communicable diseases continue to interface within the functional lives of the elderly, which mean that they are indeed living longer but are faced with lowered wellbeing. Secondly, if they are poor with proper and adequate health care coverage - which could be private or public- the implications of the cost of care along with the daily living could further add stresses to the status of life experienced by the elderly. Hence, living longer although it is directly related to reduced mortality, this does not speak to the lifestyle changes and their positive influences on the wellbeing of seniors. A study conducted by Costa, using secondary data drawn from the records of the Union Army (UA) pension programme that covered some $85 \%$ of all UA, show there is an association between chronic conditions and functional limitation - which include difficulty walking, bending, blindness in at least one eye and deafness (Costa 2002). Among the significant findings is - (i) the predictability between congestive heart failure of men and functional limitation (i.e. walking and bending). Although Costa's study was on men, this equally applies to women as biological ageing reduces physical functioning, and so any chronic ailment will only further add to the difficulties of movement of the aged, be it man or woman.

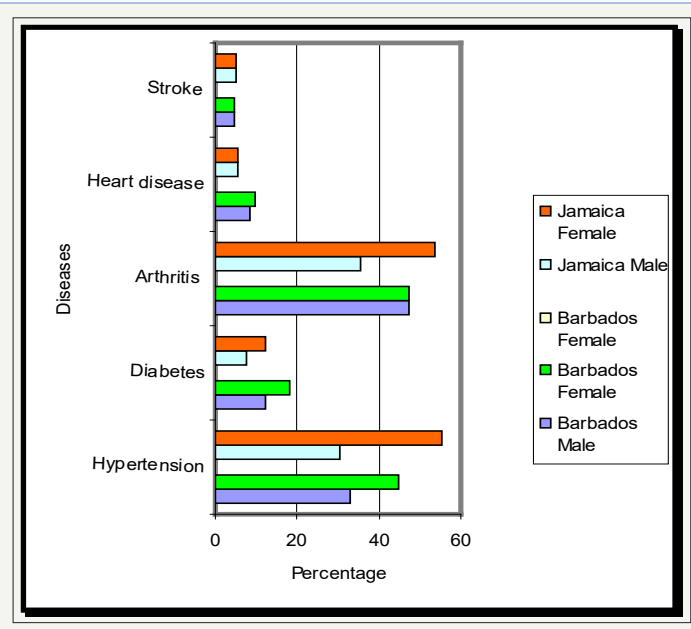

Figure 6: Leading causes of self-reported morbidity in the population of seniors, by gender in Barbados and Jamaica.

Source: Figure taken from Caribbean Food and Nutrition Institute [32]: 225. 
Like many developed countries, Jamaica is able to boast of its notable achievement in progress made toward advancing the health status of its populace, during the twentieth century - the postponement of death, lowering fertility, high nutrition and sanitation and more importantly the increasing life expectancy [50]. Analyzing data on life expectancy indicate that the country's health status is reasonably good, as the values for life span is similar to those in some First World societies - over 70 years.

Nevertheless, those positives are not sufficient to outweigh the increases in chronic non-communicable diseases-hypertension, diabetes, cardiovascular diseases, neoplasm, depression and arthritis. These diseases are on the rise in the world and are no different in Jamaica. They continue to plague those who are more so 60 years and older, of a particular socioeconomic status, and who live in rural Jamaica $[51,54,55]$. In an article published by Caribbean Food and Nutrition Institute, the prevalence rate of diabetes mellitus affecting Jamaicans is higher than in North American and "many European countries". [56]. Diabetes Mellitus is not the only challenge faced by patients, but Mc Carthy [57] argues that between $30 \%$ and $60 \%$ of diabetics also suffer from depression, which is a psychiatric illness. Such a situation further complicates the woes of the elderly as they seek to balance other psychosocial conditions with the diabetes and hypertension along with the stress which is frequently associated with the illness [49].

Furthermore, in attempting to contextualize the state of the Jamaican elderly, the researcher will provide a diagram depicting the five main causes of death by different age groups between 2002 and 2004. The diagram shows that while life expectancies are increasing, that mortality from non-communicable diseases such as heart diseases, cerebrovascular diseases and diabetes are indeed high for the elderly and are thereby lowering their wellbeing (Figure 7).

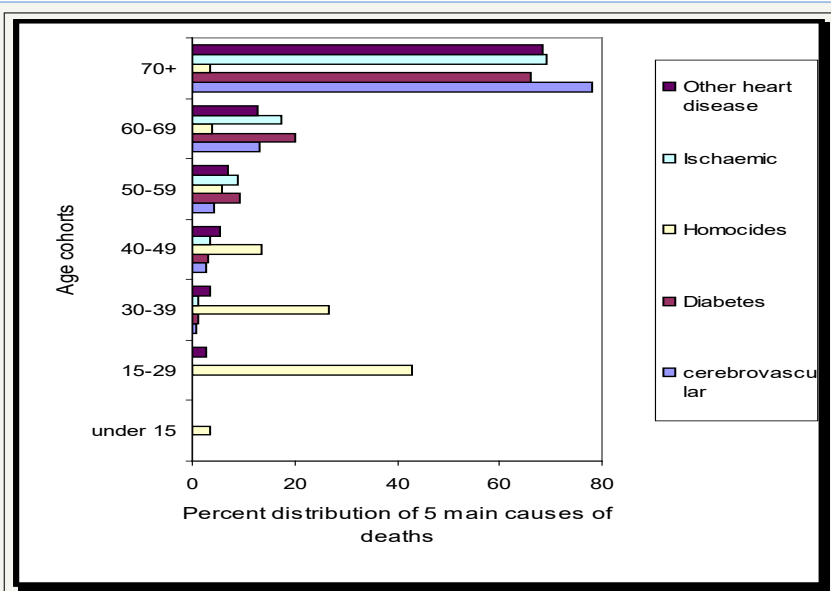

Figure 7: Percentage distribution of 5 main causes of deaths by age: 2002-2004.

Source: Adopted from the demographic statistics 2005 [38].

In 2003, data presented by the Ministry of Health Jamaica in its 'Annual Report' show that of the patients who are 65 years and older, $29.7 \%$ of them were discharged from inpatient care because of 'circulatory system diseases', and nutrition and endocrine ailments accounted for $12.6 \%$. While it is true that these diseases influence physical inactivity, the conditions of coping with these as well as the cost of care undoubtedly should be aiding to lower the wellbeing status of these people.

Findings from studies by the Planning Institute of Jamaica show that while the general health status is commendable, increases in chronic illnesses are undoubtedly eroding the quality of life enjoyed by people who are 65 years and older [48,55]. The report reveals, "In 2000, the survey also demonstrated the importance of recurrent (chronic) illness as the cause of ill health among the elderly" [55]. How is the status of elderly within general setting of higher recurrence of chronic on-communicable diseases and their severity among senior citizens? Within the macho culture of Jamaica, generally, men do not seek preventative care because it is seen as weak. Such a position is learnt from the culture, which states that boys should "suppress reaction to pain" [58].

\section{State of the Elderly: Disparity in the Sexes}

Chevannes provided the explanation for this behavior by men, that it is embedded with social learning theory. In which the young imitate the roles of society members through role- modeling of what constitute acceptable and good roles which is supported by reinforcement [58]. The gender role of sexes is not limited to Jamaica or the Caribbean but a study carried out by Ali \& Muynck [59] of street children in Pakistan found a similar gender stereotype in that nation. It was a descriptive cross-sectional study carried out during September and October 2000, of 40 school-aged street children (814 years). The sample was substantially males (80\%), with a mean age of 9 years ( \pm 2 years). The methods of data collection were

A. Semi-structured interviews, and

B. A few focus group discussions.

Ali \& Muynck [59] found that the sampled population would seek medical care based on severity of illnesses and financial situation. Another finding was that they referred to use home remedy. The reason being that mild ailment is not severity enough to restrict them from physical functioning, which mean that they 
are okay; and so, some morbidities are not for-hospital, which was so the case in Nairobi slums [60].

PIOJ \& STATIN [39] report that "The difference by gender was significant, with percent of females reporting illness, compared with 8.5 per cent of males" [48], which is the case even in 2002 that is the rate was $14.6 \%$ for females and $10.4 \%$ for males, and in 2004 it was $13.6 \%$ for females and $8.9 \%$ for male [42,52]. From statement in the JSLC 2000 "Women have traditionally utilized health care services more than men and these interactions have allowed closer monitoring and earlier diagnosis of health conditions among women" [52], then this begs the question - Are the aggregate data reported reflecting the views of the elderly or more so the females? However, what is true is that they [men] will visit health practitioners because the states of their chronic impairments are severe. This is evident in the higher number of treated cases in some ailments over that of females-from the hospitalization discharge rate for the persons 65 years and over, the rate for men is 975.1 per 10, 000 compared to 817.1 per 10, 000 females [51]. The elderly, on the other hand, are more responsive to their ill-health and seek medical attention readily, but what about the psychological state of this age cohort from things such as - loss of partner, reduction in social support, fear of being victimized and so forth.

As a result, it should not be surprising that the elderly Jamaicans seek more medical attention than other age cohorts, which is captured in them indicating more self-reported illnesses and injuries and a higher mean number of days spent in medical care $[42,48]$. Hence, is the state of the elderly worse than that which is reported in the JSLC? It should be noted that the data presented in all the official statistics on the health status of Jamaicans are still measuring health using the old biomedical model (using reported and treated illnesses and/or injuries) [51]. This approach is single focused as it omits the role environment, social exclusion, fear of crime and victimization as well as depression, and stress among other factors as determinants of individuals 'well-being.

\section{Conclusion}

This paper responds to the underlining concerns of the continuous increase in population ageing in the world. The fast ageing of populations, unless managed in a proactive manner, could impose serious challenges for policy makers in the Caribbean and Jamaica. Noteworthy is that a particular level of economic development is needed in order to deal with the challenges of this demographic transition. The demographic composition and structure of future world population and subpopulation must be understood within policy framework. The challenges that are likely to arise from an ageing population on public expenditure, on pensions and health care, particularly in the absence of reforms in pensions and health services, could lead to a build-up of public debt in developing countries in specific Caribbean islands.

In conclusion, the graying of population is not restricted to developed societies such as Japan, Germany, Canada, China, United States and Italy to name a few, but it is a current reality for nations like Barbados, Trinidad and Tobago and Jamaica. Currently Jamaica does not see the demographic transition of ageing as an issue but come 2030 or beyond, it will be a problem for many developing states including that of Jamaica. The yardstick that is used as a symbol of impending problem in demographic ageing is if a state's population 60 years or over is between 8 to 10 percent and beyond.

The early signals of demographic ageing, in Jamaica, began as early as in the 1960s, when the society began experiencing mortality and fertility declines. With the introduction of family planning in the 1970 s, the high fertility in the 1960 s has been reduced by some $300 \%$. Statistics reveal that the aged population of Jamaica is in excess of 10 percent as of 2005, within the context of an increasing decline in the population 0 to 14 years. This population (age cohort 0-14 years) stood at 40.3 percent in 1980 and in 25 years (2005), the population has been reduced to 31.2 percent. The conditions of ageing in Jamaica are not only a demographic issue but are disproportionately becoming a social, economic and political matter. In keeping with public health measure in the form of better sanitary, food and water security and quality and vaccination, mortality was cut, which is explanation for the high life expectancy of in excess of 75 years since 2004, to the best of my knowledge, no study has sought to examine the likely socioeconomic costs of ageing come 2015 to 2050 and beyond.

Despite all the gains of technology, public health, education, lifestyle behavioral practices and high life expectancy, noncommunicable diseases are on the rise and continue to plague people age 60 years or over. Thus, accompanying population ageing is more ill-well senior citizens. Within this general setting, there is a need for medical research on the way forward in-patient care as well as a demand exists for advanced quantitative assessment of the model, which will evaluate wellbeing of the Jamaican elderly. This will foster a comprehensive understanding of how health should be operationalize, and we then would be able to plan for ageing in more informed manner than what presently obtains in our society.

One of the socioeconomic and political challenges that the Caribbean in particular Jamaica faces is the difficulty with which population ageing will become an economic cost. Population ageing does not simply mean "graying" of population (or proportionately more persons ages 60 years or older or $65+$ ) but with living longer comes the responsibility of paying social security like pension for a longer period of time. Another issue that we have failed to address in all of this discussion is the lowered taxes that are going to be collected as a result of demographic ageing. Within the same construct is the dwindling of the children population and lowered fertility, which means that come 2010 and beyond the elderly dependency ratio will be increasingly more than in previous years. These developments will mean challenges for public budgets, and health care expenditures. The reality is, demographic ageing is here in the Caribbean and equally so in Jamaica. Systems and structures are needed to addressing the new demand for this age cohort, along with the biopsychosocial state of ageing.

\section{A. Notes}

${ }^{1}$ This is also called demographic ageing (or ageing of the population): It is the shifting of the age distribution (i.e. age structure) of the population towards older ages (i.e. ages 65 
years and beyond). Demographers measure this using elderly dependency ratio:

A. This is the number of people who are 65 years and older compared to the number of people who are of working ages (i.e. 15 to 64 years);

B. The proportion of the population aged 65 years and beyond (8-10\%) and/or Increase in the median or mean age of a population.

C. One scholar [16] uses 60 years and older instead of 65 years, which is the valuation used by many demographers for old age (or elderly or senior citizens).

${ }^{2}$ Population Dynamics: This is subdivided into three main areas:
a. Population change
b. Population growth and decline
c. Age-sex composition. Population Change

Address conditions relating to birth and deaths, and migration of human population. Population Growth. Changes that affect the total population because of movements in natural increases (difference between births and deaths) and net migration (difference between arrivals and departures of a particular geographic locality). Agesex composition. Inclusive of the age-sex composition are age distribution of people with a population, sex composition, along with the dependency ratios and the types of age structures.

${ }^{3}$ The shifting of the patterns of high fertility and high mortality rates to low fertility and delayed mortality

${ }^{4}$ Population - for this paper, the term denotes the 'collection of persons alive at a specified point in time who meets certain criteria [9].

\section{References}

1. (2007) United Nations world population ageing 2007. Department of economic and social affairs, population division, New York, USA.

2. Gavrilov LA, Heuveline P (2003) Aging of population. quoted in the encyclopedia of population. In: Demeny P, Mc Nicol G (Eds.), Macmillan, USA.

3. BRW (1999) Health care or wealth care? Business Review Weekly 27: 11.

4. Turner BS (1998) Ageing and generational conflicts: A reply to Sarah Irwin. British Journal of Sociology 49: 299-320.

5. World Health Organization (2002) World report on violence and health World Health Organization, Geneva, Switzerland.

6. Lauderdale DS (2001) Educational survival: Birth cohorts, period, and age effects. Demography 38(4): 551-561

7. Irma TE (2001) New african american life tables from 1935-1940 to1985-1990. Demography 38(1): 97-114

8. Kenneth GM, Kenneth CL (2000) Active Life expectancy estimates for the US. Elderly population: A multidimensional continuous-mixture model of functional change applied to completed cohorts, 1982-1996. Demography 37(3): 253-265.

9. Preston SH, Elo IT, RosenwaikeI, Hill M (1996) African american mortality at older ages: results of a matching study. Demography 33(2): 193-209.

10. James PS, Kington R (1997) Demographic and economic correlates of health in old Age. Demography 34: 159-170.

11. Rudkin L (1993) Gender differences in economic well-being among the elderly of Java. Demography 30(2): 209-226.

12. Thane P (2000) Old Age in english history past experience, present issues. Oxford University Press, England.

13. Eldemire D (1995) A situational analysis of the jamaican elderly, 1992 The Planning Institute of Jamaica, Kingston. Scientific Research 2(6):

14. Erber J (2005) Aging and older adulthood, ( $3^{\text {rd }}$ edn), In: Joan T, Erber (Eds.), New York, USA.

15. Smith KR, Waitzman NJ (1994) Double jeopardy: Interaction effects of martial and poverty status on the risk of mortality. Demography 31(3): 487-507.

16. Marcoux A (2001) Population ageing in developing societies: How urgent are the issues? Food and Agriculture Organization Women and Population Division

17. Eldemire D (1987a) The Elderly-A jamaica perspective. The elderly in the caribbean: proceedings of continuing medical education symposium. In: Grell, Gerald AC (Eds.), Kingston, University Printers, Kingston, Jamaica.

18. Eldemire D (1987b) The Clinical's approach to the elderly patient. the elderly in the caribbean: proceedings of continuing medical education symposium. In: Grell GC (Ed.), University Printers. Kingston, Jamaica.

19. Eldemire D (1994) The elderly and the family: the jamaican experience. Bulletin of Eastern Caribbean Affairs 19: 31-46.

20. Eldemire D (1997) The Jamaican elderly: A socioeconomic perspective \& policy implications. Social and Economic Studies 46(1): 75-93.

21. (1997) Pan american health organization and who health of the elderly aging and health: A shift in the paradigm.USA.

22. Barrett V (1987) Analysis of the Jamaica government's policy (1981 -1986) on institutional and community programmes for the elderly. Public Administration, University of the West Indies, Jamaica.

23. Moore EG, Rosenberg MW, McGuinness D (1997) Growing old in Canada: Demographic and geographic perspectives. Ontario, Nelson, Canada.

24. Gavrilov LA, Gavrilova NS (2001) The reliability theory of aging and longevity. J Theor Biol 213(4): 527-545.

25. Gavrilov LA, Gavrilova NS (1991) The biology of life span: a quantitative approach. Harwood Academic Publisher, New York, USA.

26. Charles Worth B (1994) Evolution in Age-structured populations $\left(2^{\text {nd }} e d n\right)$, Cambridge University Press, Cambridge, USA.

27. Brannon L, Feist J (2004) Health psychology. An introduction to behavior and health Los Angeles ( $5^{\text {th }}$ edn), Wadsworth, Ohio.

28. Bogue DJ (1999) The ecological impact of population aging. Chicago: Social Development Center (Essays in human ecology No. 4).

29. Donald TR (2003) Demographic methods and concepts. Oxford University Press, USA.

30. (2000) International Labour Organization Ageing in Asia: The growing need for social protection.

31. Wise DA (1997) Retirement Against the demographic trend: Moreolder people living longer, working less, and saving less. Demography 34(1): 83-95.

32. (1999a) Caribbean food and nutrition institute health of the elderly. Cajanus 32: 217-240.

33. Buzina K (1999) Drug therapy in the elderly. Cajanus 32: 194-200. 
34. Goulding MR, Rogers ME (2003) Public health and aging: trends in aging United States and Worldwide. Morbidity and Mortality Weekly Report 52(6): 101-106.

35. Barry M, Weinberger MB (2001) The demography of population ageing 43(42):

36. United Nations (2005c) World population prospect: The 2004 revision. Department of Economic and Social Affairs, Population Division, New York, USA.

37. United Nations (2006) Statistical yearbook $50^{\text {th }}$ issue. Department of Economic and Social Affairs, Population Division. New York, USA.

38. (2006) Statistical Institute of Jamaica Demographic Statistics, various years. Kingston, Statistical Institute of Jamaica.

39. (2003) Jamaica survey of living conditions 2002. PIOJ and STATIN, Kingston, Jamaica.

40. Grell GAC (1987) The elderly in the caribbean: Proceedings of continuing medical education symposium. University Printers, Kingston, Jamaica.

41. (2007) Cross-national research on aging. Population Reference Bureau, Washington, USA.

42. (2006) Planning institute of jamaica economic and social survey jamaica, Kingston, Jamaica.

43. (2003b) United Nations world population prospects: the 2002 revision highlights. Department of Social and Economic Affairs, Population Division New York, USA.

44. Lawson SCC (1996) Culture and Aging: the case of jamaican elderly persons. Paper presented at the Conference on Caribbean Culture. The University of the West Indies, Mona Campus, Jamaica.

45. WHO (1999) World health organization world health report 1999. Geneva, USA.

46. Apt N (1999) Protection of rights of older persons In Ageing and Health: A global challenge for the twenty-first century. Proceedings of a WHO Symposium at Kobe, Japan. World Health Organization, Geneva, Switzerland.

47. Hambleton IR, Kadene C, Broome HL, Farley BW, Fraser SH, et al. (2005) Historical and current predictors of self-reported health status among elderly persons in Barbados. Rev Panam Salud Publica 342-352.
48. Planning Institute of Jamaica (1998) Jamaica Survey of Living Conditions 1997. PIOJ and STATIN, Kingston, Jamaica.

49. Morrison E (2000) Diabetes and hypertension: Twin trouble. Cajanus 33(2): 61-63.

50. Pan American Health Organization (1990) Adult Health in the Americas: PAHO, Washington, USA.

51. (2004) Ministry of Health. Planning and evaluation branch annual report 2003. MOH, Kingston, Jamaica.

52. (2001) Planning institute of jamaica, jamaica survey of living conditions 2000: PIOJ and STATIN, Kingston, Jamaica.

53. Powell LA, Bourne P, Waller L (2007) Probing jamaica's political culture: main trends in the july-august 2006 leadership and Governance Survey. Kingston, Centre for Leadership and Governance, University of the West Indies, Mona, Jamaica.

54. (2003) Jamaica Social Policy Evaluation Annual progress report on National Social Policy Goals, Kingston, Government of Jamaica, Jamaica.

55. (1999) Planning Institute of Jamaica, Jamaica Survey of Living Conditions 1999. PIOJ and STATIN, Kingston, Jamaica.

56. Callender J (2000) Lifestyle management in the hypertensive diabetic. Cajanus 33: 67-70.

57. Mc Carthy, Frances M (2000) Diagnosing and treating psychological problems in patients with diabetes and hypertension. CAJANUS 33: 7783.

58. Barry CH (2001) Learning to be a man: Culture, socialization and gender identity in five Caribbean communities. University of the West Indies Press, Kingston, Jamaica.

59. Moazzam A, Muynck De A (2005) Illness incidence and health seeking behaviour among street children in Pawalpindi and Islamabad, Pakistanqualitative study. Child Care Health and Development 31(5): 525-532.

60. Taff N and Chepngeno G (2005) Determinants of health care seeking for children illnesses in Nairobi slums. Tropical Medicine and International Health 10(3): 240-245.
Creative Commons Attribution 4.0

International License

For possible submissions Click Here

\section{Submit Article}

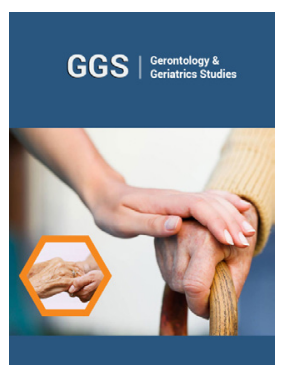

Gerontology \& Geriatrics Studies

\section{Benefits of Publishing with us}

- High-level peer review and editorial services

- Freely accessible online immediately upon publication

- Authors retain the copyright to their work

- Licensing it under a Creative Commons license

- Visibility through different online platforms 